\title{
Determination of Total Arsenic in Water and Food Samples by Pressure-induced Ionic Liquid-based Dispersive Liquid-Liquid Microextraction Method Prior to Analysis by Hydride Generation Atomic Absorption Spectrometry
}

\author{
Jamshed Alia,b, Mustafa Tüzenn,a,c, Tasneem Gul Kazi ${ }^{\text {b }}$ \\ ${ }^{a}$ Gaziosmanpasa University, Faculty of Science and Arts, Chemistry Department, 60250 Tokat, Turkey \\ b National Centre of Excellence in Analytical Chemistry, University of Sindh, Jamshoro 76080, Pakistan \\ ${ }^{c}$ King Fahd University of Petroleum and Minerals, Research Institute, Center for Environment and Water,
} Dhahran 31261, Saudi Arabia

\section{INTRODUCTION}

Arsenic (As) is a toxic metalloid that naturally occurs in combination with different minerals in the earth's crust, in water, foods, and the air (1). It is a fact that exposure to As through drinking water and food samples is toxic and carninogenic (2). Even at ultra-trace levels, it causes diseases such as skin cancer, lung cancer, bladder cancer, etc (3). The toxicity of As depends on its bonded forms. Inorganic As compounds are much more hazardous than the organic forms because the organic compound decomposes easily (4).

The types of contaminants generated from mines are basically the minerals in rocks which are dissolved in water (5). Exposure to trace level As from the atmosphere are a real challenge to measure accurately (6). In particular, enrichment of total As concentration in water and food samples is of serious concern (4). Water is an important and essential part of all life and without water life is impossible. Fresh water resources are very few and are continuously contaminated by trace and toxic elements produced from industry, power plants, mining, fertilizers, etc. $(7,8)$.

According to the World Health Organization (9), the recommended level of total As concentration in drinking water is $10 \mu \mathrm{g} \mathrm{L}^{-1}$. In gen-

*Corresponding author

E-mail:m.tuzen@gmail.com.

\section{ABSTRACT}

A pressure-induced ionic liquid-based dispersive liquid-liquid microextraction (PI-IL-DLLME) method has been developed for the determination of total arsenic (As) in water and food samples. Quantitative analysis of total As in the water and food samples was performed by using hydride generation atomic absorption spectrometry. The complexing reagent diethyldithiocarbamate formed a strong hydrophobic complex with As at $\mathrm{pH} 4$. the Ionic liquid of 1-hexyl-3-methylimida-zolium bis(trifluoromethylsul-fonyl)imide was used as the extraction medium in the aqueous solution to increase the phase transfer ratio which significantly enhances recovery of the labile hydrophobic complex. Various experimental parameters such as $\mathrm{pH}$, complexing reagent, ionic liquid, induced pressure, and centrifugation were optimized to achieve maximum recovery of the target analyte. The analytical parameters of limit of detection, limit of quantification and linear range were $0.016 \mu \mathrm{g} \mathrm{L}^{-1}, 0.055 \mu \mathrm{g} \mathrm{L}^{-1}$, and $0.062-1.25 \mu \mathrm{g} \mathrm{L}^{-1}$, respectively. The enhancement factor and relative standard deviation were found at 87.5 and $4.89 \%$, respectively. Accuracy of the developed method was checked by analysis of certified reference materials of hard drinking water, tea, and rice flour. The proposed PI-IL-DLLME method was successfully applied for the determination of total As in groundwater, surface water, and different foods. eral, the concentrations of total As in water and food are lower than the detection limits of hydride generation atomic absorption spectrometry (HG-AAS). Therefore, a preconcentration method is required to measure trace level As in water and food samples. The proposed PI-ILDLLME method minimizes matrix effects and enhances the concentration of trace level As in real samples. Some analytical microextraction methods as reported in the literature (10) are useful to determine low level concentratiions of total As but most of them are time-consuming and cause atmospheric pollution. Liquid-liquid microextraction is one of the most reliable and suitable extraction techniques for trace level determination in different environmental samples (11-13). Recently, a new microextraction technique based on dispersive liquid-liquid microextraction was used (14-16), but it also has disadvantages since the dispersive liquid decreases the distribution coefficient of the target metal into the extracting solvent. Furthermore, the extracting and dispersing solvent used in DLLME is a mostly volatile organic compound (14-20).

Room temperature stable ionic liquid (IL) methods have attracted considerable attention in recent years because they have different chemical and thermal characteristics (21). The hydrophobic property of the two phases of the liquid systems provide easy separation of low polar analytes from water (22). 
Room temperature ionic liquids have high viscosity and are low water soluble as compared to organic solvents which can significantly contribute to environmental contamination with volatile organic compounds $(23,24)$. There are many methodologies applied to investigate the dispersive ionic liquid in aqueous medium such as vortex-assisted (25) and ultrasoundassisted dispersive liquid-liquid microextraction $(26,27)$.

According to a literature survey, the ionic liquid 1-hexyl-3- methylimidazoliumbis(trifluoromethylsulfony 1)-imide is reported to be used for use the first time for entrapping the hydrophobic complex. The chelating reagent diethyldithiocarbamate (DDTC) was also used for the first the time for complexing with As in the proposed PI-IL-DLLME method.

The basic principle of the current study is to develop a pressureinduced ionic liquid-based dispersive liquid-liquid microextraction method (PI-IL-DLLME) for the separation/preconcentration of total As from water and food samples. It is also a green microextraction method. The preconcentrated water and food samples were analyzed by HGAAS. It can be stated that the present method will become useful for the assessment of other heavy metals and applicable for the analysis of different environmental samples.

\section{EXPERIMENTAL}

\section{Sample Collection}

The tap water $(n=10)$ and mineral water $(n=10)$ samples were collected from the laboratory and shops at the Gaziosmanpasa University. River water samples $(n=15)$ were collected from different location of the Yesilirmak River in Tokat city. The seawater samples $(n=20)$ were collected from different sampling locations at the Black Sea in Samsun city. The different food samples (rice, boiled wheat, chicken meat, black tea, green tea, tomato, and spinach) were purchased at different markets in Tokat city. All samples were brought to the laboratory as soon as possible to avoid contamination risk. All collected water samples from each and every sampling point were placed into washed and rinsed polyethylene bottles. These water samples were filtered with a Whatman $0.45 \mu \mathrm{m}$ filter paper and a vacuum pump. Then, two to three drops of concentrated nitric acid were added and stored at $4{ }^{\circ} \mathrm{C}$ until the determination of total arsenic.

\section{Reagents, Solutions, and Glassware}

High purity analytical reagents were used throughout the experiment. The double deionized water (Aqua max $18.2 \mathrm{M} \Omega \cdot \mathrm{cm}^{-1}$, resistivity) was obtained using an ELGA laboratory water system (Bucks, UK). The certified standard (1000 $\mathrm{mg} \mathrm{L}^{-1}$ ) of $\mathrm{As}^{3+}$ solution was obtained from Merck, Darmstadt, Germany. A number of standard calibration solutions were prepared by diluting the stock standard solution with double deionized water. The complexing reagent of sodium diethyl-dithiocarbamate trihydrate was obtained from Merck, Darmstadt, Germany. The ionic liquid of 1-hexyl-3-methylimidazolium bis(trifluoromethylsulfonyl)-imide was purchased from Merck, Darmstadt, Germany. Phosphate buffer for $\mathrm{pH}$ 2 , acetate buffer for $\mathrm{pH} 4-6$, borate buffer for $\mathrm{pH} 7$, ammonia buffer for pH 8-9 were used for the optimization of the $\mathrm{pH}$ values. The reducing reagent of sodium borohydride was obtained from Fluka Chemika, Switzerland. Analytical reagentgrade sodium hydroxide, potassium hydroxide, and ascorbic acid were purchased from Sigma-Aldrich, Czech Republic. The certified reference materials of LGC-6010 Hard Drinking Water and GBW-07605

Tea (Institute of Geophysical and Geochemical Exploration, Langfang, P.R. China), and NIST
SRM-1568a Rice Flour ((National Institute of Standards and Technology, Gaithersburg, MD, USA) were used in this experiment.

\section{Instrumentation}

A PerkinElmer $^{\circledR}$ AAnalyst $^{\mathrm{TM}} 700$ atomic absorption spectrometer, equipped with MHS-15 and HGAAS, was used (PerkinElmer, Inc., Shelton, CT, USA). The flow rate of the argon gas (99.9\%) was main-

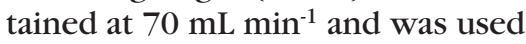
to push the hydride into the quartz cell for atomization. The light source of an electrodeless discharge lamp (EDL) was used because it provides sufficient measurable signal for the determination of As in AAS in comparison to a hollow cathode lamp. The operating current of the EDL for As analysis was set at $380 \mathrm{~mA}$ and the signals were separated at the $193.7-\mathrm{nm}$ wavelength, spectral bandwidth of 0.7 $\mathrm{nm}$ (28). The operating prameters used for HG-AAS are listed in Table I. The experimental data were calculated by usig WinLab ${ }^{\mathrm{TM}} 32$ software (PerkinElmer, Inc., Shelton, CT, USA). The NF-200 centrifuge (maximum speed $5000 \mathrm{rpm}$, timer 0-60 min, 50/60 Hz, Nuve, Turkey) was used for centrifugation. The $\mathrm{pH}$ was measured by a $\mathrm{pH}$ meter obtained from (Sartorius Professional, meter pp-15). A Milestone Ethos D model microwave oven was used for digestion of the solid samples (Sorisole-Bg, Italy).

\section{Microwave Digestion}

A $0.5 \mathrm{~g}$ amount of each sample (rice, boiled wheat, chicken meat, black tea, green tea, tomato, and spinach) and $0.10 \mathrm{~g}$ of each certified reference material (GBW-07605 Tea and NIST-SRM-1568a Rice Flour) were placed into PTFE flasks by using an analytical balance. The above-mentioned amounts of the real samples were digested by addition of $6.0 \mathrm{~mL}$ of $\mathrm{HNO}_{3}$ (65\%) with $2.0 \mathrm{~mL} \mathrm{H}_{2} \mathrm{O}_{2}(30 \%)$, and were kept up to 8 minutes at room tempera- 
ture for cooling. Then the flasks were closed and placed into the Milestone Ethos D closed vessel microwave system. The digestion program applied was $250 \mathrm{~W}$ (2 minutes), $0.0 \mathrm{~W}$ ( 2 minutes), $250 \mathrm{~W}$ (6 minutes), $400 \mathrm{~W}$ (5 minutes), $550 \mathrm{~W}$ (8 minutes), and ventilation for 8 minutes. The contents of the flasks were cooled and filtered, then diluted to $20 \mathrm{~mL}$ with double deionized water. The reagent blanks were also made using the same procedure.

\section{PI-IL-DLLME Procedure}

For the PI-IL-DLLME method, $40.0 \mathrm{~mL}$ of each standard $(\mathrm{n}=6$ each) and real samples $(n=2$ each) were placed into plastic tubes separately. The desired $\mathrm{pH}$ of the solution was adjusted by using acetate buffer, $0.75 \mathrm{mM}$, diethyldithiocarbamate. Ionic liquid of $55.0 \mu \mathrm{L}$ used as the extraction solvent was added into the studied sample solutions. The pressure of argon gas of 0.5 MPa was continuously supplied for

\section{TABLE I}

Operating Conditions of the HG-AAS System for Total As Determination

\begin{tabular}{|c|c|}
\hline Parameters & Operational Settings \\
\hline Signal measurement & Peak area absorbance \\
\hline Calibration mode & Concentration \\
\hline Measurement mode & Integration \\
\hline Operating current of EDL lamp & $380 \mathrm{~mA}$ \\
\hline Energy & 35 \\
\hline Wavelength & $193.7 \mathrm{~nm}$ \\
\hline Slit-width & $0.7 \mathrm{~nm}$ \\
\hline Slit-hight & Normal \\
\hline Atomization site & Pre-heated quartz cell atomizer \\
\hline Quartz cell & $15 \mathrm{~cm}$ path length $\times 8 \mathrm{~mm}$ iner diameter \\
\hline Heating of quartz cell & Electrothermal \\
\hline Flame & Air-acetylene \\
\hline Oxidant (air) & $17.0 \mathrm{~L} \mathrm{~min}^{-1}$ \\
\hline Fuel (acetylene) & $2.2 \mathrm{~L} \mathrm{~min}^{-1}$ \\
\hline Temperature & $900{ }^{\circ} \mathrm{C}$ \\
\hline Sample volume & $500 \mu \mathrm{L}$ \\
\hline Delay time & $40 \mathrm{~s}$ \\
\hline Constant time & $0.05 \mathrm{~s}$ \\
\hline Measurement time & $2.0 \mathrm{~s}$ \\
\hline Replicates & 3.0 \\
\hline Argon gas flow rate & $70.0 \mathrm{~mL} \mathrm{~min}^{-1}$ \\
\hline D2 Lamp background correction & On \\
\hline Diluent/Carrier solution & $1.5 \%(\mathrm{~V} / \mathrm{V}), \mathrm{HCl}$ \\
\hline $\begin{array}{l}\text { Reductant concencentration } \\
\left(\mathrm{NaBH}_{4}\right)\end{array}$ & $3 \%(\mathrm{~W} / \mathrm{V})$ in $1 \% \mathrm{NaOH}(\mathrm{w} / \mathrm{v})$ \\
\hline Stabilizing/antifoaming agent & $5 \%(\mathrm{~W} / \mathrm{V}) \mathrm{KMnO}_{4}$ \\
\hline Pre-reaction purge time & $17.0 \mathrm{~s}$ \\
\hline Reaction time & $10 \mathrm{~s}$ \\
\hline Post-reaction purge time & $40 \mathrm{~s}$ \\
\hline Sample flow rate & $7.0 \mathrm{~mL} \mathrm{~min}^{-1}$ \\
\hline $\mathrm{NaBH}_{4}$ flow rate & $1.0 \mathrm{~mL} \mathrm{~min}^{-1}$ \\
\hline
\end{tabular}

\section{Atomic Apectroscopy $\bigcup$ Vol. 38(2), Mar./Apr. 2017}

5 minutes to obtain a uniform cloudy solution. Separation of the phases was achieved by centrifugation for 10 minutes at $2500 \mathrm{rpm}$. The viscosity of the enrichment phase increases by first cooling the solution immersed in an ice bath, then discarding the bulk supernatant solution. The remaining residue was treated with $500 \mu \mathrm{L}$ acidic ethanol in order to reduce the viscosity and to facilitate the analysis. The reagent blank solution was also prepared using the same treatment. The total As concentrations in the real water and food samples were then determined by HG-AAS.

\section{RESULTS AND DISCUSSION}

\section{Optimized Experimental Parameters}

The experimental and analytical parameters which might be affected by the extraction performance and analysis of total As by PI-IL-DLLME were investigated. These included the effects of $\mathrm{pH}$, ligand concentration, ionic liquid type and volume, argon gas pressure, centrifugation rate and time, and the interfering ions in the real solution. Optimization of a parameter was performed by changing one parameter at the same time while other parameters remained constant.

\section{Effect of pH}

The complex formation between metal and complexing ligand is dependent on the $\mathrm{pH}$ of the aqueous solution. Diethyldithiocarbamate is a bidentate complexing ligand that forms complexes with more than 30 elements of the periodic table at an acidic pH (29). In the present method, the $\mathrm{pH}$ was studied in the working range of 1.0-9.0 to investigate the selectivity, sensitivity, and the separation of total As from water and food samples. Extraction of any metal from the solution into the enriched phase depends on the formation constant of the metal complex 
(30). Quantitative maximum recovery is observed at the $\mathrm{pH}$ range of 3.0-5.0 of the aqueous solution of the target metalloid. The results illustrated that maximum recovery was obtained at $\mathrm{pH} 4.0$ as is shown in Figure 1. Thus, the $\mathrm{pH}$ value of 4.0 was selected as optimum for further analysis by PI-IL-DLLME.

\section{Effect of Complexing Ligand Concentration}

The complexing reagent DDTC is a bidentate ligand that forms a stable hydrophobic complex with arsenic. The concentration effect of DDTC for maximum As recovery was studied in the range of 0.1-1.0 $\mathrm{mM}$. Figure 2 shows that the recoveries of total As increases when the concentration of DDTC is increased. Initially, a recovery below $30 \%$ was observed without DDTC which shows that the chelating reagent is necessary for maximum recovery. Quantitative recovery was obtained after addition of $0.70 \mathrm{mM}$ DDTC. The optimum concentration of 0.75 mM DDTC was selected for further analysis with the proposed PI-ILDLLME method.

\section{Effect of Type of Ionic Liquid and Volume}

Selection of ionic liquids (ILs) is based on their miscibility and hydrophobic property in solution to entrap the hydrophobic complex. The following ionic liquids for entrapping hydrophobic complexes were investigated: 1-butyl-3-methylimidazolium hexafluorophosphate (IL-1), 1-hexyl-3-methylimidazolium bis (trifluoromethylsulfonyl)-imide (IL-2), and 1-butyl-3-methylimidazolium tetrafluoroborate (IL-3). Many experiments were performed for each IL Figure 3 shows that a >95\% recovery of the target analyte was obtained with IL2. Thus, IL2 was selected as the extraction solvent due to its hydrophobic character to entrap the As-DDTC complex. Recovery of total As remarkably increased when the volume of IL was increased. Maximum recovery of total As was achieved in the range of 50-60 $\mu \mathrm{L}$ ionic liquid. Therefore, $55 \mu \mathrm{L}$ was selected as an optimum volume for further study with the PI-IL-DLLME method.

\section{Effect of Induced Argon Gas Pressure}

Uniformly dispersive IL in solution is the major challenge to achieving the desired recovery and to decrease the time to obtain thermodynamic equilibrium. There are many procedures reported in the literature for dispersing IL, but the nature of the IL might not only affect the results but also not be environmentally friendly $(23,26)$. Figure 4 shows that the recovery of total As was below 50\% without induced argon gas because IL was not uniformly dispersed in the solution. In the present study, the induced argon gas pressure was studied in the range of 0.1 to 0.8 $\mathrm{mPa}$ to disperse the IL in the aqueious phase making it into a homogeneous solution. Maximum recovery of total As was achieved at $0.5 \mathrm{MPa}$ of argon gas and was used as the optimum value for further study.

\section{Effect of Centrifugation Rate and Time}

Centrifugation plays a vital role in achieving a robust separation of total As from real water and food samples. Centrifugation at shorter rates did not significantly affect the total As extraction. An experiment to explore the outcome of the PI-ILDLLME in the range 500 to 3500 rpm was performed. Quantitative recovery of enriched total As was achieved using over $2500 \mathrm{rpm}$ as is shown in Figure 5. It was found that the centrifugation time of 10 minutes at $2500 \mathrm{rpm}$ was best for complete separation. No noticeable improvement was observed by increasing the time and rpm rate.

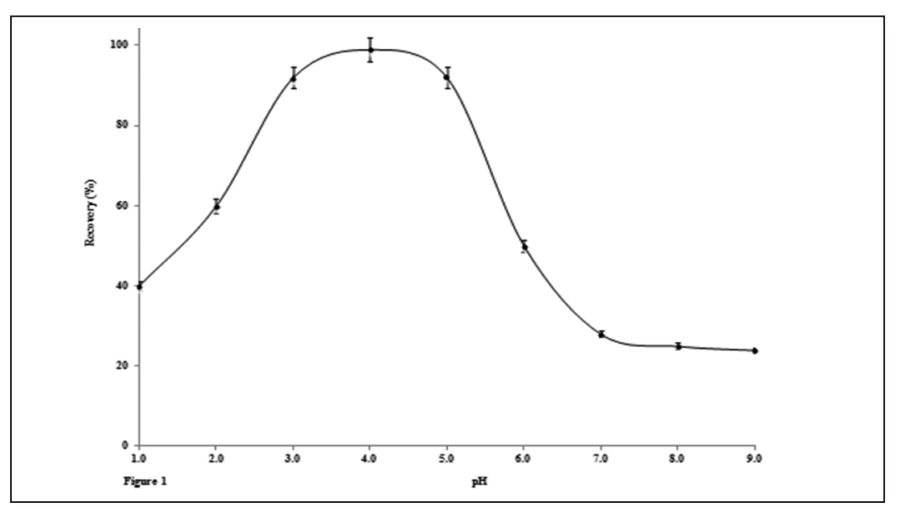

Fig. 1. Effect of $\mathrm{pH}$ on the \% recovery of total As in PI-ILDLLME method, extraction conditions: concentration of DDTC $(0.75 \mathrm{mM})$, volume of IL $(55.0 \mu \mathrm{L})$, induced pressure of argon gas (0.5 MPa) and centrifugation (2500 rpm for $10 \mathrm{~min}$ ).

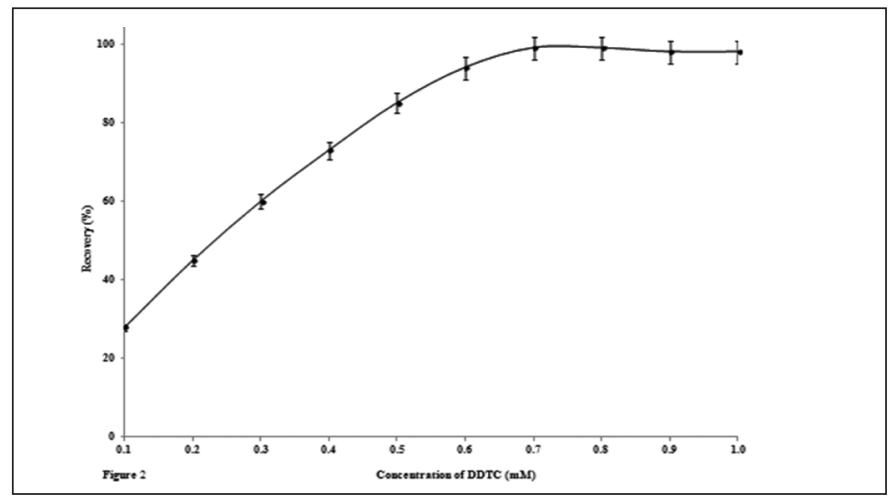

Fig. 2. Effect of DDTC concentration on the \% recovery of total As in PI-IL-DLLME method, extraction conditions: $p H$ of solution (4.0), volume of IL $(55.0 \mu \mathrm{L})$, induced pressure of argon gas ( $0.5 \mathrm{MPa}$ ) and centrifugation (2500 rpm for $10 \mathrm{~min}$ ). 


\section{Atomic Spectroscopy \\ Vol. 38(2), Mar./Apr. 2017}

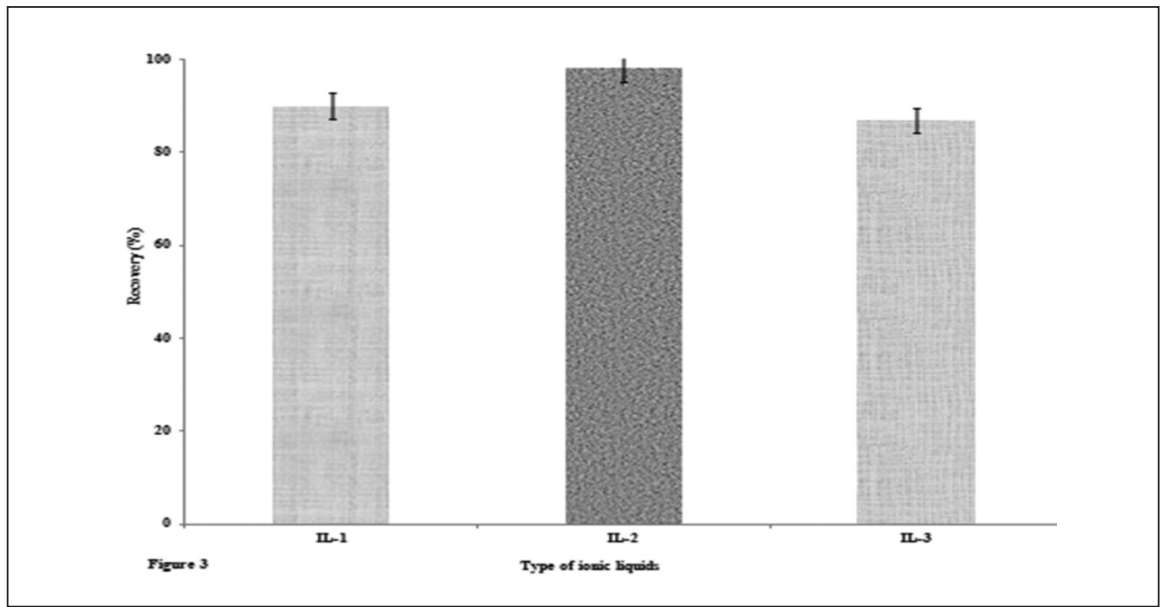

Fig. 3. Effect of the ionic liquid types and volume on the (\%) recovery of total As in PI-IL-DLLME method, extraction conditions: pH of solution (4.0), concentration of DDTC $(0.75 \mathrm{mM})$, induced pressure $(0.5 \mathrm{MPa})$ of argon gas and centrifugation (2500 rpm for $10 \mathrm{~min}$ ).

\section{Effect of Interfering Ions}

It is well known that environmental samples such as water and food have many coexisting metals. Sometime these ions are also responsible for stable chelating complexes with DDTC in the optimized $\mathrm{pH}$ range and might affect recovery of the analytes. This competitive effect of chelating with coextracted metal ions can manipulate the complex As-DDTC and decrease the extraction recovery. Various studies (31-38) have investigated the effect of interfering ions in conjunction with the microextraction method.

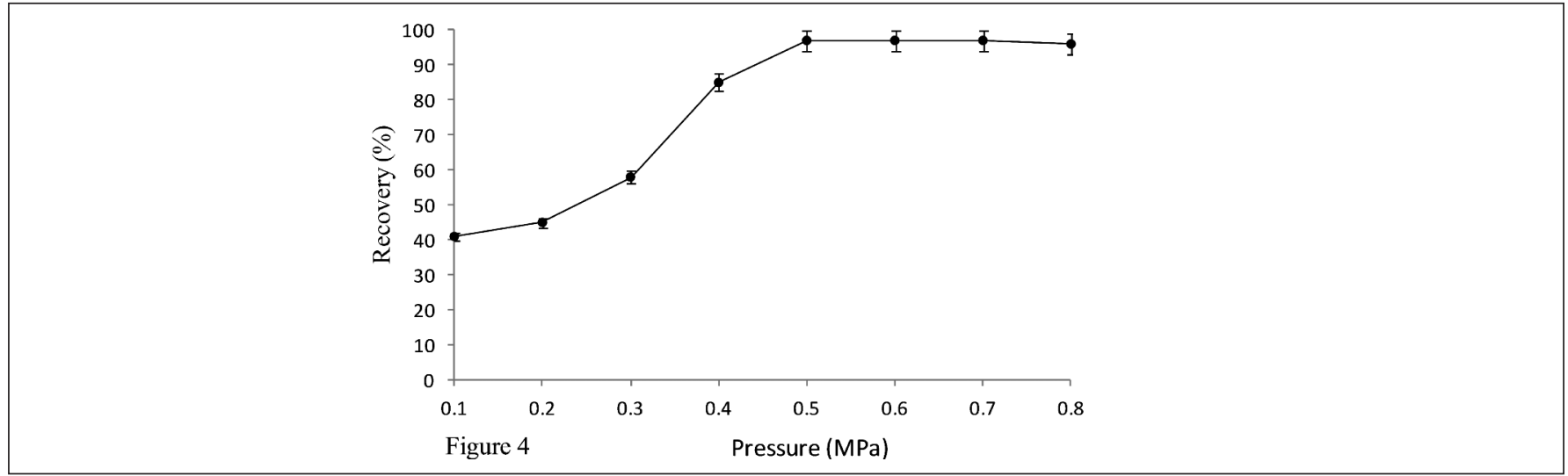

Fig. 4. Effect of induced pressure of argon gas on the (\%) recovery of total As in PI-IL-DLLME method, extraction conditions: pH of solution (4.0), concentration of DDTC $(0.75 \mathrm{mM})$, volume of IL $(55.0 \mu \mathrm{L})$ and centrifugation $(2500 \mathrm{rpm}$ for $10 \mathrm{~min})$.

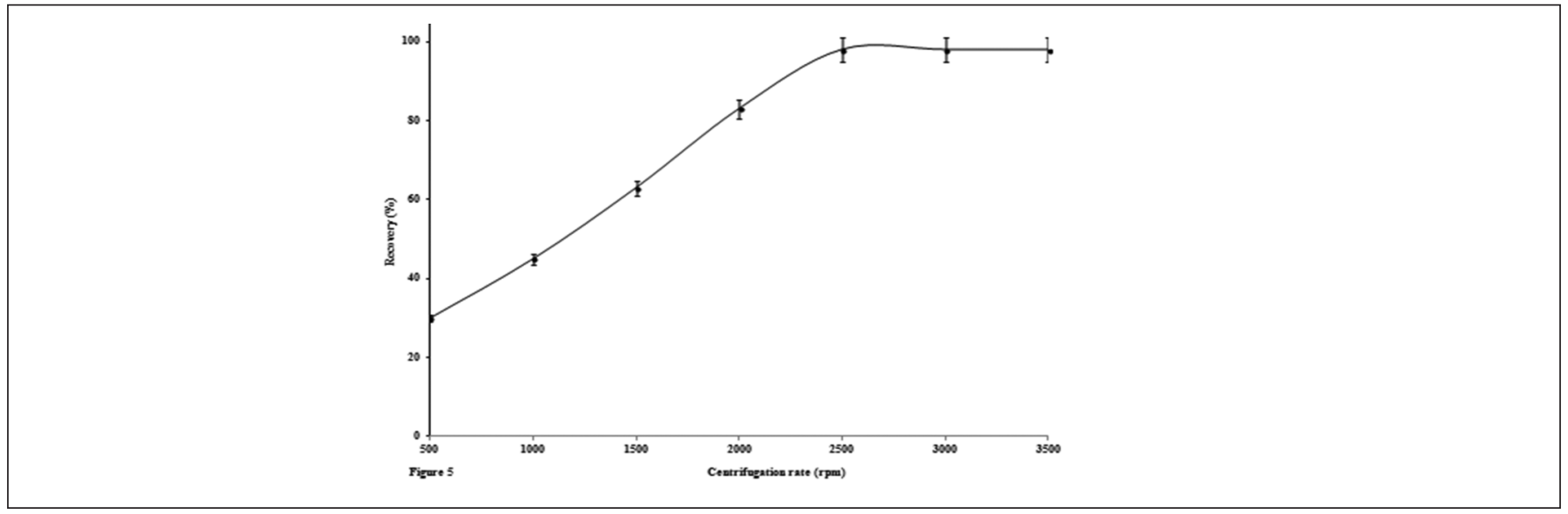

Fig. 5. Effect of the centrifugation rate on the (\%) recovery of total As in PI-IL-DLLME method, extraction conditions: pH of solution (4.0), concentration of DDTC $(0.75 \mathrm{mM})$ and volume of IL $(55.0 \mu \mathrm{L})$. 
To establish the effect of coexisting ions, a model solution of As at different interfering ions to analyte ratio was studied by applying the proposed PI-IL-DLLME method. The results listed in Table II show that the proposed method allows for the interference-free determination of trace level total As in real water and food samples. Mostly alkali and alkaline earth elements have been observed to have a very low effect on the selectivity of the desired analyte ions which might

TABLE II

Tolerance Limit of Interfering Ions for the Determination of Total As

\begin{tabular}{lcc}
\hline Ions & $\begin{array}{c}\text { Tolerance } \\
\text { Limit } \\
\left(\mathrm{mg} \mathrm{L}^{-1}\right)\end{array}$ & $\begin{array}{c}\text { Recovery } \\
(\%)\end{array}$ \\
\hline $\mathrm{Na}^{+}$ & 10,000 & $98 \pm 2^{\mathrm{a}}$ \\
$\mathrm{K}^{+}$ & 2000 & $96 \pm 1$ \\
$\mathrm{Ca}^{2+}$ & 5000 & $98 \pm 1$ \\
$\mathrm{Mg}^{2+}$ & 5000 & $97 \pm 2$ \\
$\mathrm{Al}^{3+}$ & 25 & $98 \pm 2$ \\
$\mathrm{Fe}^{3+}$ & 25 & $99 \pm 2$ \\
$\mathrm{~Pb}^{2+}$ & 25 & $97 \pm 1$ \\
$\mathrm{Zn}^{2+}$ & 25 & $99 \pm 1$ \\
$\mathrm{Cu}^{2+}$ & 25 & $97 \pm 1$ \\
$\mathrm{Cd}^{2+}$ & 25 & $96 \pm 2$ \\
$\mathrm{Ni}^{2+}$ & 50 & $98 \pm 2$ \\
$\mathrm{Cl}^{2+}$ & 15,000 & $97 \pm 2$ \\
$\mathrm{~F}^{2}$ & 2500 & $99 \pm 2$ \\
$\mathrm{NO}_{3}{ }^{-}$ & 5000 & $97 \pm 2$ \\
$\mathrm{SO}_{4}^{2-}$ & 5000 & $98 \pm 2$ \\
$\mathrm{PO}_{4}{ }^{3-}$ & 5000 & $99 \pm 2$ \\
\hline
\end{tabular}

$\mathrm{a}=$ mean \pm standard deviation. be due to their low tendency to form stable complexes.

\section{Validation of PI-IL-DLLME Method}

The analytical capability and performance of the PI-IL-DLLME method prior to analysis by HG-AAS was investigated using the optimized experimental and analytical parameters. Using the PI-IL-DLLME method, the calibration graph for a preconcentrated standard solution was linear in the range of $0.062-1.25 \mu \mathrm{g} \mathrm{L}^{-1}$ with a correlation coefficient of 0.9968 . The limit of detection (LOD) is defined as three times the standard deviation divided by the slope of 10 blank measurements. The limit of quantification (LOQ) is defined as 10 times the standard deviation divided by the slope of 10 blank measurements. The calculated LOD and LOQ of the detection technique for total As was $0.016 \mu \mathrm{g} \mathrm{L}^{-1}$ and 0.055 $\mu \mathrm{g} \mathrm{L^{-1 }}$, respectively. The enhancement factor (EF) was calculated by the slope ratio of the calibration graph with and without the preconcentration method. Thus, the calculated EF was found 87.5 for the PI-IL-DLLME method. Precision of the method was checked by the percentage relative standard deviation which was $4.89 \%(n=10$, $0.325 \mu \mathrm{g} \mathrm{L}^{-1}$ As). The accuracy of the PI-IL-DLLME method was checked with certified reference materials of water and food samples. The developed method resulted in excellent accuracy and had a recovery higher than $97 \%$ for all CRM samples (see Table III). These results indicate that the pro-

TABLE III

Results of Total As in CRMs of Water and Food Samples

\begin{tabular}{llccc}
\hline CRMs & Code No. & $\begin{array}{c}\text { Certified } \\
\text { Values } \\
\left(\mu \mathrm{g} \mathrm{g}^{-1}\right)\end{array}$ & $\begin{array}{c}\text { Measured } \\
\text { Values } \\
\left(\mu \mathrm{g} \mathrm{g}^{-1}\right)\end{array}$ & $\begin{array}{c}\text { Recovery } \\
(\%)\end{array}$ \\
\hline Hard Drinking Water & LGC-6010 & 0.052 & $0.051 \pm 0.004$ & 98 \\
Tea & GBW-07605 & 0.28 & $0.29 \pm 0.04$ & 103 \\
Rice Flour & NIST-SRM-1568a & 0.29 & $0.28 \pm 0.03$ & 97 \\
\hline
\end{tabular}


enhancement factor for preconcentration of trace level As in the water and food samples (see Table V). The other analytical parameters of linear range, LOD, LOQ, RSD, and $\mathrm{EF}$ are comparable to the literature reported methods for the determi- nation and extraction of total As in environmental samples.

\section{CONCLUSION}

A new pressure-induced ionic liquid-based dispersive liquid-liquid microextraction (PI-IL-DLLME)
Amic $_{\text {Spectroscopy }}^{\text {tomic }}$

method was developed for the preconcentration and separation of trace level arsenic in water and food samples. The developed method was coupled with HG-AAS for quantification of total As. All samples were collected from differ-

TABLE IV

Results of Total As Concentration in Real Water and Food Samples With Standard Recovery Method

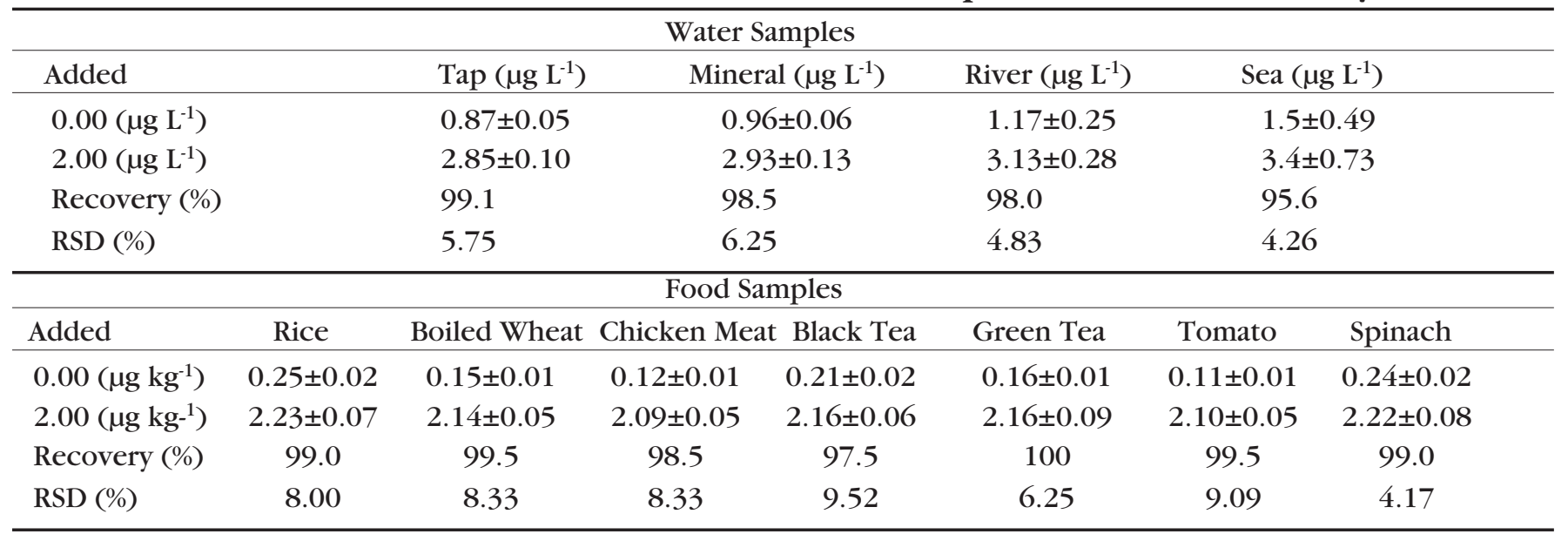

TABLE V

Comparisons of Analytical Parameters of the Developed Method With Previously Reported Methods

\begin{tabular}{|c|c|c|c|c|c|c|c|}
\hline Method & Techniques & $\begin{array}{l}\text { Linear Range } \\
\quad\left(\mathrm{ug} \mathrm{L}^{-1}\right)\end{array}$ & $\begin{array}{l}\mathrm{LOD}^{\mathrm{a}} \\
\left(\mathrm{ug} \mathrm{L}^{-1}\right)\end{array}$ & $\begin{array}{l}\mathrm{LOQ}^{\mathrm{b}} \\
\left(\mathrm{ug} \mathrm{L}^{-1}\right)\end{array}$ & $\begin{array}{l}\mathrm{RSD}^{\mathrm{C}} \\
(\%)\end{array}$ & $\mathrm{EF}^{\mathrm{d}}$ & Ref. \\
\hline PI-IL-DLLME & HG-AAS $^{\mathrm{h}}$ & $0.062-1.25$ & 0.016 & 0.055 & 4.89 & 87.5 & Current \\
\hline$S P E^{f}$ & HG-AAS & $0.03-40$ & 0.010 & 0.031 & NDo & 20 & (31) \\
\hline SPE & HG-DC-AFS ${ }^{i}$ & $0.01-2.00$ & 0.004 & 0.013 & 4.20 & 25.4 & (32) \\
\hline SPE & GF-AAS $^{j}$ & $0.27-5.25$ & 0.05 & 0.063 & 4.1 & 50 & (33) \\
\hline SPE & ICP-MS $^{\mathrm{k}}$ & $20.0-60.0$ & 0.09 & ND & 6.02 & 50.0 & (34) \\
\hline FI-SPg & HG-AFS ${ }^{1}$ & $0.10-10.0$ & 0.023 & 0.076 & 1.30 & 11 & (35) \\
\hline SPE & HG-AAS & ND & 0.013 & 0.043 & 8.00 & 36 & (36) \\
\hline SPE & HG-ICP-OES ${ }^{\mathrm{m}}$ & $1.15-25.2$ & 1.30 & ND & 1.3 & 28 & (37) \\
\hline SPE & FI-HG-AAS ${ }^{n}$ & $0.21-8.26$ & 0.05 & 0.35 & 8.0 & 20 & (38) \\
\hline
\end{tabular}

${ }^{a}$ Limit of detection.

${ }^{\mathrm{b}}$ Limit of quantification.

c Relative standard deviation.

${ }^{\mathrm{d}}$ Enrichment factor.

e Pressure-induced ionic liquid-based dispersive liquid liquid microextraction.

${ }^{\mathrm{f}}$ Solid phase extraction.

${ }^{g}$ Flow injection online sorption preconcentration.

${ }^{\mathrm{h}}$ Hydride generation atomic absorption spectrometry.

${ }^{\mathrm{i}}$ Hydride generation double channel atomic fluorescence spectrometry.

j Graphite furnace atomic absorption spectrometry.

${ }^{\mathrm{k}}$ Inductively couple plasma mass spectrometry.

${ }^{1}$ Hydride generation atomic fluorescence spectrometry.

${ }^{\mathrm{m}}$ Hydride generation-inductively coupled plasma- optical emission spectrometry.

${ }^{\mathrm{n}}$ Online flow injection hydride generation atomic absorption spectrometry.

${ }^{\circ}$ not determined. 
ent sampling locations and markets of Tokat city, Turkey.

It was found that the total As concentrations in the different real samples of water and food were lower than the permissible level as estasblished by the World Health Organization for drinking water $\left(10 \mu \mathrm{g} \mathrm{L}^{-1}\right)$.

The analytical parameters such as linear range, LOD, LOQ, RSD, and EF were excellent. The advantages of the PI-IL-DLLME method are sensitivity, selectivity, simple operation, and low cost extraction. In comparison to other analytical techniques, hydride generation atomic absorption spectrometry is the more suitable and reliable technique for the determination of total As due to the volatile nature of As. Other advantages of the proposed method include low detection limit and high enhancement factor. Therefore, this newly developed PIIL-DLLME method is a good alternative for the determination of trace level total As in environmental complex matrixes.

\section{ACKNOWLEDGMENT}

The author Jamshed Ali is grateful to The Scientific and Technological Research Council of Turkey (TUBITAK) for the award of the 2216 Research Fellowship Program for International Researchers. Thanks are also due to the Gaziosmanpasa University for providing all laboratory facilities to conduct this research work. Dr. Mustafa Tuzen thanks the Turkish Academy of Sciences for financial support.

Received October 5, 2016.

\section{REFERENCES}

1. K.L. Ackley, J.A. Caruso, J.G. Alonso, J.R. Encinar, B. Michalke and C.C. Chery, Handbook of elemental speciation: Techniques and Methodology (John Wiley \& Sons, England, 2003) 147.
2. D.P. Torres, M.A. Vieira, A.S. Ribeiro and A.J. Curtius, J. Braz. Chem. Soc. 18, 728, (2007).

3. J. Ali, T.G. Kazi, J.A. Baig, H.I. Afridi, M.S. Arain, K.D. Brahman and A.H. Panhwar, Environ. Sci. Pollut. Res. 22, 8559 (2015). doi: 10.1007/s11356-0144038-6.

4. J. Ali, T.G. Kazi, J.A. Baig, H.I. Afridi, M.S. Arain, N. Ullah, K.D. Brahman, S.S. Arain and A.H. Panhwar, Environ. Sci. Pollut. Res. 22, 19251 (2015). doi: 10.1007/s11356-015-5058-6.

5. A.K. Singh, M. Mahato, B. Neogi, B. Tewary and A. Sinha, Environ. Earth Sci. 65, 49 (2012). doi: 10.1007/s12665-011-1064-2

6. M. Arain, T. Kazi, J. Baig, M. Jamali, H. Afridi, A. Shah, N. Jalbani and R. Sarfraz, Food Chem. Toxicol. 47, 242 (2009). doi: 10.1016/j.fct.2008.11.009.

7. K.D. Brahman, T.G. Kazi, H.I. Afridi, S. Naseem, S.S. Arain and N. Ullah, Water Res. 47, 1005 (2013). doi:10.1016/j.watres.2012.10.042.

8. W. Li, L. Chen, T. Zhou, Q. Tang and T. Zhang, Mining Sci. Tech. (China) 21, 715 (2011)

9. G. WHO, World Health Organization 216, 303 (2011).

10. Z. Gong, X. Lu, M. Ma, C. Watt and X.C. Le, Talanta 58, 77 (2002).

11. J.A. Baig, T.G. Kazi, M.B. Arain, A.Q. Shah, G.A. Kandhro, H.I. Afridi, S. Khan, N.F. Kolachi and S.K. Wadhwa, Anal. Sci. 27, 439 (2011).

12 J. Pawliszyn, Sampling and sample preparation for field and laboratory: fundamentals and new directions in sample preparatio. (Elsevier, 2002).

13. M. Ma and F.F. Cantwell, Anal. Chem. 71, 388 (1999).

14. S. Berijani, Y. Assadi, M. Anbia, M.R.M. Hosseini and E. Aghaee, J. Chroma. A 1123, 1 (2006).

15. M. Rezaee, Y. Assadi, M.R.M. Hosseini, E. Aghaee, F. Ahmadi and S. Berijani, J. Chroma. A 1116, 1 (2006).

16. E. Zhao, W. Zhao, L. Han, S. Jiang and Z. Zhou, J. Chroma. A 1175, 137 (2007).

17. M. G.Lopez, I. Rodriguez and R. Cela, J. Chroma. A 1166, 9 (2007).

18. D. Nagaraju and S.D. Huang, J. Chroma. A 1161, 89 (2007).

19. H. Farahani, P. Norouzi, R. Dinarvand and M.R. Ganjali, J. Chroma. A 1172,
105 (2007).

20. H. Chen, H. Chen, J. Ying, J. Huang and L. Liao, Anal. chim. acta. 632, 80 (2009).

21. A. Berthod, M.R. Angel and S.C.Broch, J Chroma. A 1184, 6 (2008).

22. E. Aguilera-Herrador, R. Lucena, S. Cárdenas, M. Valcárcel, TrAC Trends in Analytical Chemistry 29 (2010) 602.

23. M. Koel, Critical Reviews in Analytical Chemistry 35 (2005) 177.

24. A.E. Visser, R.P. Swatloski, W.M. Reichert, R. Mayton, S. Sheff, A. Wierzbicki, J.H. Davis and R.D. Rogers, Environ. Sci. Technol. 36, 2523 (2002).

25. F. Shah, E. Yilmaz, T.G. Kazi, H.I. Afridi and M. Soylak, Anal. Methods 4, 4091 (2012).

26. Y. Zhang and H.K. Lee, Anal. Chim. Acta. 750, 120 (2012).

27. H. Bai, Q. Zhou, G. Xie and J. Xiao, Talanta 80, 1638 (2010).

28. S. Chatrchyan, V. Khachatryan, A. Sirunyan, A. Tumasyan, W. Adam, T. Bergauer, M. Dragicevic, J. Ero, C. Fabjan and M. Friedl, Phys. Rev. D 89, 2007 (2014).

29. L.B. Escudero, E.M. Martinis, R.A. Olsina and R.G. Wuilloud, Food chem. 138, 484 (2013).

30. O.D. Sant Ana, L.S. Jesuino, R.J. Cassella, M.S. Carvalho and R.E. Santelli, J. Braz. Chem. Soc. 14, 728 (2003).

31. H. Erdogan, O. Yalcinkaya and A.R. Turker, Desalination 280, 391 (2011).

32. H. Wu, X. Wang, B. Liu, Y. Liu, S. Li, J. Lu, J. Tian, W. Zhao and Z. Yang, Spectrochim. Acta Part B: Atom. Spectro. 74, 66 (2011).

33. Y. Jiang, Y. Wu, J. Liu, X. Xia and D. Wang, Microchim. Acta 161, 137 (2008).

34. M. Mulugeta, G. Wibetoe, C.J. Engelsen and W. Lund, J. Anal. Atom. Spectro. 25, 169 (2010).

35. X.P. Yan, X.B. Yin, X.W. He and Y. Jiang, Anal. Chem. 74, 2162 (2002).

36. O.D. Uluozlu, M. Tuzen, D. Mendil and M. Soylak, Food Chem. Toxicol. 48, 1393 (2010).

37. R. Gil, N. Ferrua, J. Salonia, R. Olsina and L. Martinez, J. Hazard. Mater. 143, 431 (2007).

38. G.T. Macarovscha, G.G. Bortoleto and S. Cadore, Talanta 71, 1150 (2007) 


\title{
Activated Carbon Cloth (ACC) as Efficient Adsorbent for Trace $\mathrm{Cu}(\mathrm{II}), \mathrm{Co}(\mathrm{II}), \mathrm{Cd}(\mathrm{II}), \mathrm{Pb}(\mathrm{II}), \mathrm{Mn}(\mathrm{II})$, and $\mathrm{Ni}(\mathrm{II})$ as 0-0-diethylphosphorodithioic Acid Chelates for the Enrichment From Water and Soil Samples
}

\author{
Mustafa Soylak $^{\text {a** }}$, Demet Acar ${ }^{\mathrm{a}}$, and Zeid A. ALOthman ${ }^{\mathrm{b}}$ \\ A Erciyes University, Faculty of Sciences, Department of Chemistry, 38039 Kayseri, Turkey \\ b Chemistry Department, College of Science, King Saud University, Riyadh-11451, Kingdom of Saudi Arabia
}

\section{INTRODUCTION}

The exposure of trace chemicals and heavy elements to humans in today's urban and industrial society has risen dramatically in the last 50 years (1-3). Trace elements such as $\mathrm{Cu}, \mathrm{Fe}, \mathrm{Zn}$, and $\mathrm{Mn}$ are necessary elements for the human body and lack of these elements can cause various diseases $(4,5)$, while elements such as $\mathrm{As}, \mathrm{Cd}, \mathrm{Hg}$, and are toxic (6-8). The concentrations of trace elements are generally lower than the detection limits of some of the detection techniques, such as atomic absorption spectrometry (914). In addition, matrix effects from concomitant ions can cause problems for these analyses (15-18). Thus, preconcentration-separation methods are generally used prior to the determination of analyte elements (19-22).

Solid phase extraction is considered superior to other preconcentration-separation techniques due to its simplicity, consumption of small volumes of organic solvent, and the ability to obtain a high preconcentration factor and high analytical speed (23-27) In addition, novel solid phases for acid and bases, high surface area and high adsorption capacities have also been reported (28-35). Activated carbon cloth (ACC) is one of the adsorbents for solid phase extraction of trace analytes from environmental samples (36-40). It has mechanical strength, high surface

* Corresponding author

E-mail: soylak@erciyes.edu.tr

tel: +903524374933 ,

\section{ABSTRACT}

A preconcentration procedure based on the adsorption of $\mathrm{Cu}(\mathrm{II})$, $\mathrm{Co}$ (II), $\mathrm{Cd}(\mathrm{II}), \mathrm{Pb}$ (II), $\mathrm{Mn}$ (II), and $\mathrm{Ni}(\mathrm{II})$ as their O-O-diethylphosphorodithioic acid chelates on activated carbon cloth (ACC) is presented. The analytical parameters including $\mathrm{pH}$ of the working media, amount of O-O-diethylphosphorodithioic acid, and eluent type, etc., were optimized. The effects of matrix components were also investigated. The analyte elements were quantitatively recovered at $\mathrm{pH} 6.0$ with $0.5 \mathrm{mg}$ O-O-diethylphosphorodithioic acid and $10 \mathrm{~mL} 3 \mathrm{M} \mathrm{HNO}_{3}$ was used as the eluent. Addition recovery tests were also performed for real samples. The relative standard deviations were generally lower than $5 \%$. The validation of the proposed procedure was checked by the analysis of SPS-WW2 Wastewater certified reference material. The solid phase extraction method was applied to the separation-preconcentration of the analyte elements from environmental samples, including natural water and soil samples from Kayseri, Turkey.

area, stability for acids and bases, and the possibility for regeneration.

In the present work, a solid phase extraction procedure for trace $\mathrm{Cu}(\mathrm{II}), \mathrm{Co}(\mathrm{II}), \mathrm{Cd}(\mathrm{II}), \mathrm{Pb}(\mathrm{II})$, $\mathrm{Mn}(\mathrm{II})$, and $\mathrm{Ni}$ (II) as their O-Odiethylphosphorodithioic acid on activated carbon cloth (ACC) has been established. The analytical parameters for the quantitative recovery of the analyte elements were optimized and applied to the determination of these analytes in water and soil samples from Kayseri, Turkey.

\section{Experimental}

\section{Instrumentation}

A PerkinElmer ${ }^{\circledR}$ Model 3110 flame atomic absorption spectrom eter (FAAS) (PerkinElmer, Inc., Shelton, CT, USA) was used for the determination of the analyte elements. All instrumental settings used were as recommended by the manufacturer. All measurements were carried out with an air/acetylene flame. A centrifuge ALC PK 120 Model (Buckinghamshire, England) was used for centrifuging All pH measurements were carried out using a Sartorius PT-10 digital pH meter (Germany), equipped with a combined glass electrode.

\section{Standard Solutions and Reagents}

All solutions were prepared with reverse osmosis purified Milli- ${ }^{\circledR}$ water $(18.2 \mathrm{M} \Omega \cdot \mathrm{cm}$, Millipore Corporation, Milford, MA, USA). All reagents and solvents were of analytical reagent grade and used as received. The stock solutions (1000 $\mathrm{mg} / \mathrm{L}$ ) of the analyte elements and other cations were prepared by dissolving the appropriate amounts of nitrate salts of the analyte elements in reverse osmosis purified water.

O-O-diethylphosphorodithioic acid ammonium salt was purchased from Alfa Aesar, Heysham, England (CAS No: 1068-22-0). 0.1\% (m/v) O-O-diethylphosphorodithioic acid ammonium salt was prepared daily 